\title{
VELÁZQUEZ Y ARACNE, EL MITO Y LA ÉPOCA
}

\author{
Ricardo SANMARTÍN
}

Resumen: Si miramos hacia atrás, a una época dorada, no es por apartar la vista del horror de nuestros días. La curiosidad histórica y la antropológica están ambas motivadas por el común deseo de entendernos, de encontrar algo que nos ayude a mejorar la intelección del alma humana, su inserción en el mundo que crea y las construcciones que fabrica. Las diversas producciones culturales, tanto en el tiempo como en el espacio, llaman siempre la atención de la Antropología por razones similares, erigiéndose ante la mente como preguntas sugerentes, como incógnitas cuyo reto aceptamos admirados al sospechar alguna semejanza con nuestra hora a pesar de tan amplias diferencias. Bien mirado, tampoco fue tan dorado el barroco siglo XVII, ni a nuestro sobrecogido cambio de siglo podemos negarle el costoso bienestar alcanzado. Entonces y ahora vivimos inmersos en largos y hondos procesos de cambio de incierto destino. Sin duda es condición del presente negarnos el rostro del futuro, mientras que al mirar al pasado jugamos con la ventaja de creer que hemos entendido la imagen de aquel destino al que entonces, sin conocerlo, se dirigian los espanoles del reinado de Felipe IV. Aunque no podamos olvidar lo acontecido, deberíamos suspender lo que de su futuro sabemos para situarnos en la piel de aquel siglo. De ese modo quizá pudiésemos acercarnos más a quienes tampoco entonces conocian hacia donde acabaría llevándoles la historia que construian. Pero tan artificiosa operación sólo puede ofrecer algún resultado si acompañamos nuestra mirada con la de los hombres de la época que estudiamos.

No pretendo comparar ambos momentos, ni estudiar la España del XVII, sino una sola imagen de aquel siglo, aunque para hacerlo tenga que arroparla con otras imágenes y palabras. Me centraré en una obra de arte: La Fábula de Aracne, esto es, el cuadro de las Hilanderas de Velázquez, una pin- 
tura de su última etapa, en la plenitud de su madurez, muy comentada por la crítica y sobre la que, sólo con riesgo, cabe vislumbrar posibles sentidos todavía no aprendidos. Supliendo con la imaginación la escasez de noticias de su autor podemos escuchar, al mirar el cuadro, alguna lección que D. Diego Velázquez dejó elegantemente oculta, oscurecida, al modo barroco, en la compleja elaboración de su obra. No estoy con ello reduciendo el potencial semántico del arte a la intención del autor de una obra. Sin duda ésa es una de sus fuentes. Pero no creo que podamos limitarnos, al estudiar un cuadro, al análisis de aquellas intenciones. También éstas tienen sus razones, y si para entenderlas hemos de reconocer la circunstancia de la época, la tradición en la que se insertan y frente a la cual se yerguen, estaremos integrando en el análisis, de modo inevitable, algo que supera la intención misma del autor. En ocasión similar a la que me encuentro, pero estudiando el retrato del conde-duque de Olivares, C. Lisón se preguntaba "¿hasta dónde podemos penetrar nosotros, hoy y ahora, en una pintura del siglo XVII? [...] ¿podemos leer narrativas latentes?» ". A lo que a renglón seguido respondía:

"Ciertamente que a esta distancia no podemos captar en su riqueza las valencias de pensamiento y creación de Velázquez, las vivencias exactas del conde y la experiencia de los que vieron entonces el lienzo porque nuestro vocabulario emotivo es diferente y porque aquel mundo evanescente ya ha desaparecido. Disponemos por otra parte, de un equipo cognitivo cultural y de una matriz histórico-barroca que favorecen una cierta penetración en las condiciones sociales de la época”.

Sin duda es en esa relación con la época, como contexto y horizonte de la obra, donde podemos enraizar la comprensión. Claro está que eso implica reconocer que la obra no es sino parte de algo más amplio, y es ahí, al caer en la cuenta de ello, cuando empezamos a ampliar el análisis hacia ámbitos cada vez más sociales y colectivos, históricos y culturales. Así advertimos que no podemos legítimamente limitar el estudio a la obra, al cuadro, como si éste fuese algo que, bastándose a sí mismo, en sí mismo tuviese todo su sentido, independientemente de su hacerse o de su gozarse. Si nos limitáramos en el

1 LISON TOLOSANA, C. 2000: El conde-duque de Olivares en corveta regia. Una mirada desde la Antropología. Anales de la Fundación Joaquín Costa, Huesca, p. 238. 
estudio del arte al cuadro mismo, a su análisis plástico e iconográfico, tomándolo como única unidad de análisis, estaríamos reduciendo su estudio a una mera lectura de los símbolos que contiene, y así estaríamos universalizando una interpretación descontextualizada. Sin duda hemos de referirnos al cuadro. Pero éste no es más que el punto de encuentro, el momento de un proceso, el cruce o el nudo de un sinfín de conexiones. Algunas de ellas fueron sin duda establecidas por el autor conscientemente, con intención acorde con su concepto, traduciendo a su modo el encargo recibido, previendo el uso que por su destino tendría la obra. Pero muchas otras conexiones debieron muy probablemente resultarle a Velázquez, como a cualquier creador, inevitables. No podía Velázquez evitar tener tras de sí la tradición plástica que la historia hasta el XVII le ofrecía. Contar con ella, bien como modelo o, a la contra, como objeto al que oponerse e innovar así en otras direcciones, es siempre ineludible. Tampoco cabría zafarse de la historia y la cultura de la época, de su mundo circundante. $\mathrm{Ni}$ la propia biografía está siempre en nuestras manos de un modo pleno. Nada de eso es el cuadro y, sin embargo, contribuye a su hacimiento. Es más, aunque Velázquez no lo quisiera, no podría evitar que su obra, una vez terminada, entrase en juego con el horizonte entero que en cada época porta en su mirada quien la contempla. La obra, una vez hecha, escapa del dominio de su autor al cruzarse con los mundos dispares de quienes la usan. Claro que éstos tampoco pueden evitar en su uso atender a lo que en el cuadro consta, a lo que en él puso su autor, a lo que en su época significaba. Pero sobre todo ello también resulta inevitable que se sumen nuevos horizontes culturales, por referencia a los cuales la obra se resignifica. Es más, tanto lo que el autor no puede evitar, como lo que conscientemente pretende, se apoya e incide en los valores, creencias y categorizaciones propias de su tiempo. Ese es pues un marco irrenunciable para la comprensión incluso cuando ésta pueda ser plural y variable.

En esa misma línea de reflexión podemos encontrar más razones para no limitar el análisis al cuadro estudiándolo en su unicidad, de un modo aislado. A ello nos obliga la obvia constatación de que ésa, como cualquiera de las demás obras, es fruto de su autor. Si algún tipo de unidad podemos todavía reconocer en el hecho personal, la naturaleza diacrónica de la biografía, su desarrollo - aunque se obren cambios en el sujeto que a sí mismo se hereda en el tiempo- opera trenzando un hilo de transformaciones en el que cabe apreciar un cierto sentido razonable. Ese hilo biográfico se entrama a su vez con los avatares y peripecias que, por su parte, sufre la sociedad y la época en 
la que el autor trabaja. Del progresivo entretejido de ambos se desprende la conveniencia de considerar cualquiera de las obras, todo cuanto en ella consta, atendiendo a su dinámica, a su inserción en la trayectoria del autor, como un eslabón más encadenado al resto de sus obras. De ahí que, al contemplar la trayectoria de cada artista, no podamos dejar de verle como alguien atento al devenir de su época, cuya reflexión sobre los problemas que observa acaba dejando una cierta huella en esa sucesión de obras. Sin duda, en la medida en que los artistas han ido ganando una mayor autonomía a la hora de realizar su trabajo, ese papel escrutador de su tiempo ha encontrado mayores posibilidades expresivas. Eso no significa que estuviese ausente por entero en la pintura por encargo la presencia del juicio del autor. Aun cuando se amoldase a lo pedido, siempre cupo sugerir, aunque fuere de un modo agazapado, el propio sentir y pensamiento, en unos más, en otros autores menos. En el caso de Velázquez cabría entrever esa presencia no sólo por la compleja composición de muchas de sus obras, que sobrepasa a lo poco que sabemos de lo indicado en el encargo. Además de evidenciarse aquel juicio en la verdad desvelada por su penetrante mirada en el alma del retratado, sea Papa, rey o esclavo, hemos de recordar la experiencia de libertad vivida en su segundo viaje a Italia, donde "había un cada vez más poderoso mercado de arte, que permitía que un artista con talento pudiera sobrevivir sin tutela, lo que suponía crear con total independencia» ${ }^{2}$. A la vuelta de ese segundo viaje no sólo nos presenta a una tan joven reina Mariana de Austria perdida al borde de su propio inmenso y rígido traje, o la decadencia en el rostro de Felipe IV, sino también la atrevida desnudez de la Venus del espejo, la elaborada reflexión de Las Meninas y, como corolario de ella, un denso comentario de la fábula de Aracne en sus Hilanderas. Nada de ello es tan sólo un eficaz cumplimiento de un encargo. Incluso así, es a un maestro a quien se le encarga cada una de esas obras porque de él, más que de otro, se espera que haya, en su concepto y ejecución, una diferencia, una aportación certera.

No aislar el estudio de una obra, no limitarlo a ella misma ni cifrarlo en una total dependencia de la explícita intención de su autor, no significa que su contextualización no se realice a través de quien la crea. No podemos dejar de

2 Calvo Serraller, F. 1999: Velázquez. Península, Barcelona, p. 92. Sobre el impacto de la experiencia italiana en la obra de Velázquez véase Manuela B. MENA MARQUês: "Velázquez e Italia: Las metamorfosis del arte de la pintura» en Velázquez. El Papa Inocencio X de la Galleria Doria Pamphilj, Roma. Catálogo. Madrid, 1996. Museo del Prado. 
lado qué constituye Las Hilanderas ni quién fue Velázquez. Si en la época, como marco y horizonte, se inscribe la obra, quien en primer lugar no podía evitar tal inscripción fue su autor. «Fue, pues, Velázquez intérprete de ella y de hondas necesidades espirituales sentidas en su tiempo" ${ }^{3}$.

Por esa condición de vehículo y crisol de la cultura nos referimos al autor, y al hacerlo nos encontramos con un Velázquez flemático y reflexivo, informado, lector de latín, italiano y francés, culto, «excepcionalmente ilustrado para su tiempo $[\ldots]$ de mente amplia e inclinaciones científicas y humanísticas" ${ }^{4}$, formado en el ambiente intelectual de su suegro, Francisco Pacheco, orientado por el diplomático Rubens, instalado en el entorno de confianza del mayor monarca de la época y, siendo pintor de cámara del rey desde los veinticuatro años, se trataba de alguien que estaba al tanto de la vida de palacio y de la corte, donde se benefició de varios cargos como ujier de cámara y aposentador mayor. Cortesano con ambición de nobleza y conocedor por experiencia de un temprano y duradero éxito con el sufrido coste de la envidia, vivió cerca del poder y la nobleza durante toda su vida adulta. Contando con su formación y capacidad, con los testimonios de Pacheco, del propio Felipe IV - que reconocía temer la flema del pintor, pues no se arredraba éste desvelando en sus retratos las huellas de la edad y de sus pecados sobre el rostroo como recogió años después Palomino al describirlo como excediendo en la noticia de las lenguas, y en la filosofia á muchos de su tiempo" ${ }^{5}$, «igual con Pacheco en lo especulativo", seguidor de aquella pintura italiana y española en la que apreciaba "armonía $[. .$.$] por lo extraño del pensar, y viveza de los con-$ ceptos" ${ }^{6}$, por todo ello no podemos sino reconocer en Velázquez a un agudo y fino analista de la condición humana que además ocupaba un lugar privilegiado para el escrutinio de la época. Si en vez de la pintura su medio expresivo hubiese sido la palabra, mediante el ensayo o la crónica, probablemente tendríamos en él un legado de penetrantes análisis sobre su tiempo. A esa actitud crítica que pretendemos atribuirle a Velázquez alude Ortega como clave para entender su obra. Decía Ortega:

3 Lafuente Ferrari, E. 1999: Velázquez o la salvación de la circunstancia. Institució Alfons el Magnànim. Valencia, p. 38.

4 MofFitT, J.F. 1991: Velázquez, prácrica e idea: estudios dispersos. Universidad de Málaga y Colegio de Arquitectos en Málaga, p. 96.

5 Palomino, A. 1797: El museo pictórico y escala óptica. Tomo segundo, Madrid, p. 479.

6 Tal fue el caso del pintor Luis TRISTÁN, quien supone ya una transición del manierismo al naturalismo del barroco. Ibid. p. 481. 
"No se puede entender a Velázquez si no se le contempla como la estricta contraposición a los entusiasmos de su tiempo. Es un error suponer que los grandes hombres son siempre representativos de su época, como no se entienda por ser representativo ser la contraposición de su época. La verdad es con máxima frecuencia lo inverso: el grande hombre es grande porque se opone a su tiempo [...aun cuando...] el modo de su oposición no tiene la apariencia de tal»?

Valga como fácil ejemplo la indudable contención y sobriedad en el estilo de Velázquez frente al gusto popular por la truculencia de las penitencias como las que se vieron en la procesión del Viernes Santo en el Madrid de 1623, en la que participaron miembros de distintas órdenes religiosas:

"unos con calaveras y cruces en las manos; otros con sacos y cilicios, sin capuchas, cubiertas las cabezas de ceniza, con coronas de abrojos, vertiendo sangre; otros con sogas y cadenas a los cuellos, y por los cuerpos; cruces a cuestas, grillos en los pies, aspados y liados, hiriéndose los pechos con piedras, con mordazas y huesos de muertos en las bocas y todos rezando salmos. Asi pasaron por la calle Mayor y Palacio y volvieron a sus conventos con viaje de más de tres horas, que admiró la Corte y la dejó llena de ejemplos, ternura, lágrimas y devoción" ${ }^{8}$.

Pero no sólo en el estilo, sino en los contenidos de sus obras, como veremos, cabe apreciar la reflexión moral frente a su época. En el caso de Velázquez no cabe duda de que su cercanía al poder y su dependencia de la autoridad por las funciones que desempeñaba, condicionaba la claridad de sus expresiones críticas. Con todo, ese mismo oscurecimiento y matización de la crítica, sobre todo cuando se dirigía al poder, era algo que tipificó la época barroca, en la que se cultivó "la disimulación y otras formas a las cuales, desde un punto de vista de moral tradicional, se calificarían de insinceras" ". La inviable crítica directa se canaliza a través de la alusión, la omisión, la sugerencia o la evocación, cuyos

7 Ortega y Gasset, J. 1983 (1947): Velázquez. Espasa-Calpe, Madrid, p. 155. Para un estudio antropológico-social del arte entendido como contrapunto al contexto de la época véase R. SANMARTIN, 1993: Identidad y creación. Ed. Humanidades, Barcelona.

8 Anales de Madrid, ed. preparada por Fernández Mar'f́n, Madrid, 1971, p. 249, citado por MARAVAlL, J.A. 2000: La cultura del Barroco. Ariel, Barcelona, p. 337.

9 Maravall, J.A. op. cit. p. 402. 
contenidos hay que descifrar, dando "como resultado la "forma confusamente clara" del Barroco (Casalduero), es decir, "la relativa y confusa claridad" de Wölfflin, que se opone a la absoluta claridad del Renacimiento" ${ }^{10}$. Al claroscuro une Velázquez su impresionismo, como a su flema la expresividad del alma o del movimiento detenido, su tensión vital. Así como Cervantes nos presenta un loco cuerdo, los bufones de Velázquez resultan melancólicos ${ }^{11}$. Esa tensión entre opuestos nos avisa de que no es simple la operación del arte. Velázquez, como decía Ortega, se opone a la época sin parecerlo no sólo por su estilo, sino también porque su oposición no es plena, sino selectiva, matizada; no es elemental, sino compleja. Los elementos que toma de su época o de la tradición, a la vez que de ese modo la reflejan, los usa como vehículo de su crítica moral. También "un hombre al oponerse a su tiempo pertenece a él y lo lleva dentro» ${ }^{12} \mathrm{Si}$ usa la norma no es para doblegarse ante su peso, sino para ponerla al servicio de su concepto.

\section{El cuadro de las Hilanderas}

Abundando en las características señaladas, Jonathan Brown reconoce que "Velázquez puede ser entendido como el ejemplo más consumado de la unión de arte y sabiduría, la realización del ideal académico del pintor erudito" ${ }^{13}$, tras lo cual constata, sin embargo, que "cuando pudo demostrarse que las Hilanderas era la Fábula de Aracne se ahondó aún más su misterio, lejos de esclarecerse» ${ }^{14}$. Es sobre todo a Diego Angulo a quien, siguiendo la sugerencia de E. Harris, se deben importantes avances en el análisis de las Hilanderas. El fue quien determinó el claro precedente de Miguel Angel y el contenido mitológico del cuadro que refiere la competición entre Minerva y Aracne ${ }^{15}$. Antes se pensaba que el cuadro ofrecía un ejemplo maduro del naturalismo fotográ-

10 HatzFeld, H. 1972: Estudios sobre el Barroco. Editorial Gredos, Madrid, p. 133.

11 Véase H. HARTZFELD op. cit. p. 412.

12 Ortega y Gassat, J. 1983 (1946): Goethe-Dilthey. Revista de Occidente en Alianza Editorial, Madrid, p. 207.

13 BROWN, J. 1988: Imágenes e ideas en la pintura española del siglo XVII. Alianza Forma. Madrid, p. 110.

14 Ibid.

15 ANGulo IÑıgueZ, D. 1999 (1947): Velázquez. Cómo compuso sus principales cuadros y otros escritos sobre el pintor. Istmo. Madrid. 
fico de Velázquez quien, como aposentador, visitaba con unas damas la fábrica de tapices de Santa Isabel y, cayendo en cuenta de la belleza de la instantánea, la inmortalizó sin arrepentimientos ni cọrrecciones. Como Angulo reconoce, no era ésa la forma de proceder de Velázquez. Sus complejas composiciones presuponen un trabajo de reflexión y estudio que no se limita al aspecto plástico de la obra, sino también a su contenido ideológico, a su potencial semántico. Lo que vemos, pues, con esa apariencia de naturalidad encierra muchas sorpresas.

El primer plano de la Fábula de Aracne lo protagonizan dos hilanderas, una de ellas, la joven, de espaldas al espectador. A su izquierda, de frente, otra de más edad, sujetando en su mano izquierda el hilo de un huso. Tras ellas, otras tres jóvenes obreras, con la cabeza baja, yendo a lo suyo, ayudan a las hilanderas. El segundo plano, tras unos altos escalones, aparece otra escena más iluminada en la que tres elegantes damas contemplan un tapiz en el que se representa el rapto de Europa. Entre el tapiz y las damas aparece Minerva con casco reprimiendo a Aracne. El relato mitológico cuenta que Aracne, una joven lidia, admirada por su habilidad en el tejido de tapices, orgullosa de ello, no aceptaba que dijesen que su capacidad era don recibido de Minerva, a quien retó en contienda. Minerva, disfrazada de vieja se le presentó aconsejándole que no lo hiciese y pidiese perdón a la diosa, rogándole aceptase su consejo fundado en la sabiduría de su vejez y matrimonio. Ante el rechazo de Aracne, Minerva dejó el disfraz de vieja y se le manifestó en su esplendor para celebrar la contienda. Minerva tejió motivos que representaban la superioridad de su padre Júpiter y los castigos que recibieron los mortales que no guardaron el respeto a los dioses. Por su parte Aracne, además del rapto de Europa por parte de Júpiter bajo la forma de un toro, representó en su tela los demás engaños usados para sus distintos lances amorosos. Minerva, ante la deshonra de ver pintados los vicios de los dioses, rompió la tela de Aracne y le golpeó en la frente. Ésta, al verse menospreciada intentó ahorcarse. Minerva, apiadándose de Aracne le salvó la vida pero le castigó transformándola en araña y condenándola a pender siempre de su propia tela como ejemplo.

El relato, más ampliamente descrito, se recogía y comentaba en al menos tres de los libros que Velázquez poseía. Además Velázquez pintó las Hilanderas en una época en la que repetidamente trabajó sobre temas mitológicos, no sólo al pintar la Venus del espejo con Cupido, al reproducir las copias de Juan B. ${ }^{a}$ del Mazo sobre Palas y Aracne y del Juicio de Midas de Rubens (o Apolo y Pan, según J. Gállego) al fondo de sus Meninas, o pintando Mercurio y Argos, sino 


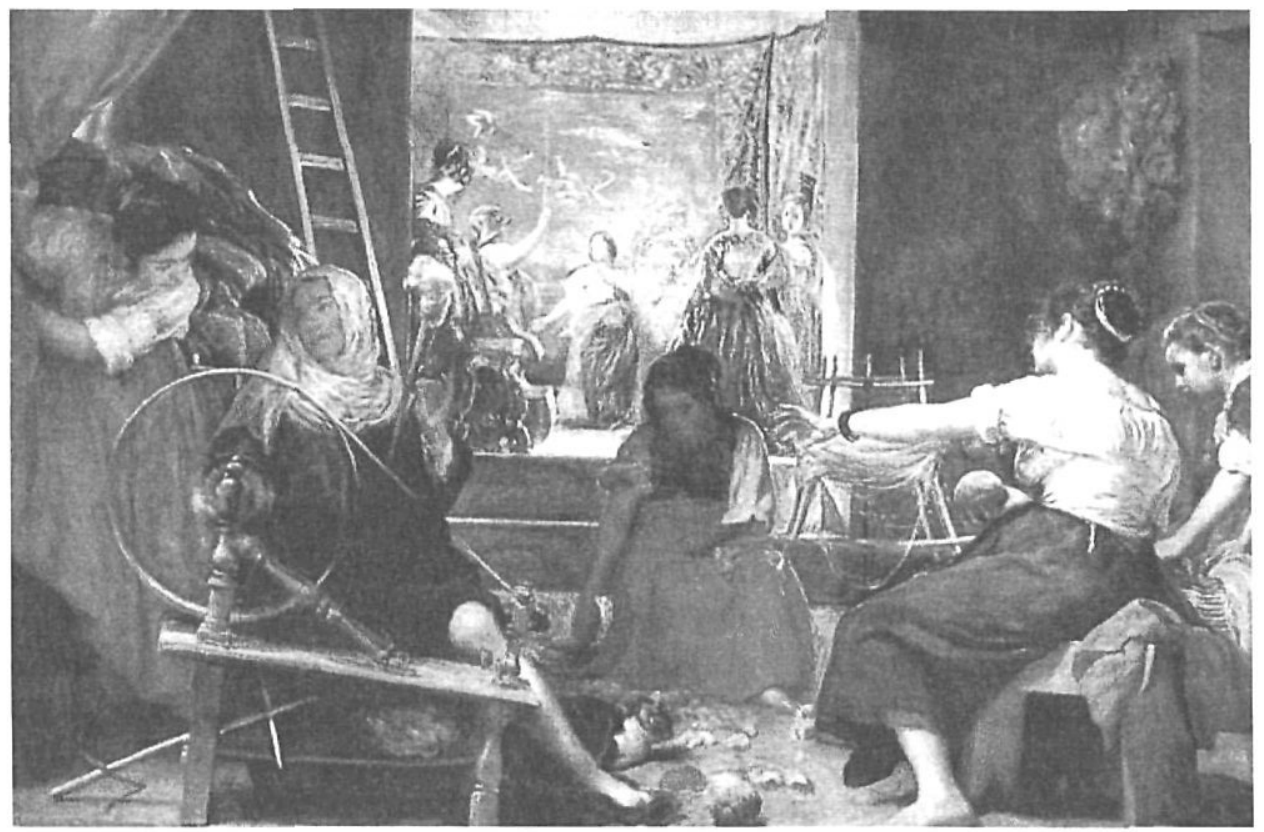

también al diseñar los frescos del techo del Salón de los Espejos, eligiendo como tema que habían de pintar Carreño, Colona, Rici y Miteli un amplio comentario mitológico sobre Júpiter, Vulcano, Prometeo y su hermano y la engañosa Pandora ${ }^{16}$. Parece pues más probable que su atención se centrase no sobre una anecdótica visita al taller de tapices, sino en el contenido de la fábula de Aracne. Con todo, como reconocía J. Brown, sigue sin desvelarse así su sentido. Es más, hay varios elementos que oscurecen y dificultan la intelección. ¿Qué sentido tiene que junto a las tres damas incluya Velázquez un instrumento musical que parece ser una lira o una viola? Lo mismo podemos preguntar sobre esa escala que parte de detrás de la hilandera vieja y no conduce a ninguna parte, sobre los enormes escalones que separan ambas estancias, sobre el sentido de que todos los personajes sean mujeres o ante el atrevimiento de pintar los pies desnudos de ambas hilanderas, desnudando la pierna entera precisamente de la más vieja. No menos peculiar es su uso de la luz, tan cinematográfico y ubicuo, iluminando, como si su pincel fuese un foco, cue-

16. Véase Palomino, A. Op. cit. pp. 512-513. 
llos y espaldas a contraluz y ocultándonos la fuente de la misma. Para poder entender todo eso hemos de salir del cuadro y situarlo ante el horizonte de cada uno de los marcos contextuales a los que más arriba aludimos: la tradición plástica, la trayectoria del autor y los problemas morales de la época.

\section{El horizonte de la tradición}

Diego Angulo detectó y subrayó cómo las hilanderas que protagonizan el primer plano son una transformación de dos de los ignudi que Miguel Ángel pintó en el techo de la Capilla Sixtina del Vaticano. Las posiciones se repiten salvo la cabeza y brazo izquierdo de la hilandera vieja. Probablemente por ello, para dejar constancia del origen de su idea, a modo de cita sugerente, dejó Velázquez desnuda la pierna menos esperable. Una manera de evaluar la importancia que su autor dio a esa pista o cita académica reside en que para hacerlo tuvo que transgredir las normas aprendidas en la academia de Pacheco en contra del desnudo. Pero el hecho, revelador de los apuntes que de su primer viaje a Italia trajo a España, no hace sino trasladar la pregunta. ¿Qué sentido puede tener transformar en mujeres a dos poderosos desnudos masculinos dejando una clara huella de su origen a modo de clave interpretativa? Sin duda, a la transformación que sufre Aracne asocia Velázquez la transformación que su crítica mirada aprecia sobre la fortaleza de los hombres travistiéndolos en hilanderas. Pero ¿quiénes son esas dos hilanderas, una joven y otra vieja?. La crítica identifica a la joven con Aracne y a la vieja con Minerva. Con todo, la posición de la cabeza de Minerva, bajo la apariencia de una vieja hilandera, no encaja con la del desnudo de Miguel Angel, ni con la dirección a Aracne de sus consejos. Por ello dudaba Angulo de que fuese Minerva la vieja hilandera. Para afirmarlo cabe recordar otra obra que posiblemente conoció Velázquez y cuyo tema refuerza la interpretación que sugiero. Me refiero a un grabado del siglo XV de Cristofano Robetta sobre Adán y Eva con sus hijos ${ }^{17}$. La posición de la cabeza y sobre todo la posición del huso, son exactas a las de la vieja hilandera. No era ése el único caso en el que al representar a Eva se le mostraba con el huso como

17 Una copia puede verse en la Biblioteca del Museo del Prado en el tomo 25/13, comentarios al tomo 25 de The Ilustrated Bartsh. La figura de Eva recuerda en parte a la Venus de Lorenzo DI CREDI, de 1490, que consta en la Galería de los Uffici de Florencia, ciudad que visitó Velázquez en su segundo viaje. Agradezco a Carlos Granés la fotocopia facilitada y los datos sobre su localización. 
signo del castigo por su ambición de ser como dios mismo. En realidad consta desde temprana fecha y de forma muy repetida en distintas iglesias de toda la cristiandad. También pudo conocer Velázquez ese tipo de representación en las iglesias de S. Marcos y S. Petronio a su paso por Venecia y Bolonia. Así entendida esa nueva huella de la tradición, Velázquez transforma el ignudi en una vieja hilandera que, aunque no se dirija de palabra a Aracne, encarna en su figura el contenido del mismo mensaje al fundir a Eva y Minerva cristianizando el mito. La mayor desnudez de la vieja hilandera le recordaba al culto observador de la época Barroca una triple referencia, no sólo el ignudi de Miguel Angel, sino también la desnudez de Eva y, en tercer lugar, la pierna de la propia Minerva manchada por los frutos del deseo de Hefesto que Minerva secó y limpió con lana. Arrojada al suelo aquella lana dio nacimiento a su hijo Erictonio, rey de Atenas, quedando sugerida, aún en potencia, esa semilla sucesoria a la corona en el gurruño de lana a los pies de la hilandera.

Si cabe así despejar las dudas de Angulo, no lo hacemos por un mero afán de precisión historicista, sino en busca de una línea que ayude a la comprensión del sentido. Si podemos ver esa figura como una Minerva que en su misma composición encarna plásticamente su mensaje, se refuerza la interpretación al percibir que la escala surge desde la espalda y la cabeza de Minerva. Señalaba Moffitt que

"esta escala es, por supuesto, el símbolo tópico de la ascensión del Conocimiento, es decir, la que conduce desde las cosas mundanas a los reinos más elevados del pensamiento puro. Se le llamaba generalmente la scala sapientis, y aparece utilizada con este significado en innumerables grabados e ilustraciones de libros del Renacimiento" ${ }^{18}$.

Se asocia así de nuevo a la vieja hilandera una imagen adicional capaz de representar la relación de Atenea o Minerva con el saber, las artes y la filosofía. En torno a su mano coinciden visualmente la escala de la sabiduría, el huso del castigo, la lira y el final de los escalones que conducen a la estancia iluminada en la que Minerva se manifiesta como tal. La lira, en el plano del lienzo, establece la transición entre las dos figuras de Minerva: como hilandera y como diosa, resultando así que el símbolo de la música y la poesía, de la creación

18 MoffitT, J.F. op. cit. p. 87. 
artística, revela la concepción del arte como aquella actividad que permite al hombre transitar entre ambos mundos, entre el trabajo y el espíritu, ese mundo al que aspira Aracne y que con su mano izquierda parece arañar desde el ángulo opuesto de tamaños escalones. Con todo, es difícil asignar un solo sentido a los símbolos que usa la pintura. La lira y la escala también indican otros significados que enriquecen con ambigüedad las posibilidades abiertas por la obra. La transición entre los dos niveles del cuadro $-\mathrm{y}$ de la vidapodría haberse simbolizado de otro modo. Elegir la lira o una viola aludiendo más a la música que a la poesía implica un matiz conscientemente buscado. Por su parte, la escala o conduce a la oscuridad o a ninguna parte. Aunque está situada en la misma dirección ascendente hacia el foco de la luz, el muro impide el acceso ${ }^{19}$. En ambos casos necesitamos ir al contexto de la época para mejorar nuestra comprensión. Pero antes de observar ese más amplio contexto del Barroco deberíamos considerar la inserción de las Hilanderas en la trayectoria de su autor.

\section{La trayectoria del autor}

Aun cuando no hay unanimidad entre la crítica al fechar la ejecución del cuadro, en lo que todos coinciden es en que se trata de una obra posterior a las Meninas (1656), bien de 1657 o bien de 1659. En ambas obras, en las Meninas y en las Hilanderas, falta la constancia clara del encargo. En el primer caso J. Gállego ${ }^{20}$ duda si la obra se debe a encargo de Felipe IV o a iniciativa del pintor. En todo caso, el cuadro estaba ya en el despacho de verano del rey en 1666. En el segundo J. Moffitt reconoce que también falta la constancia directa del encargo, pero infiere que pudo ser fruto del que recibió en octubre de 1659 para decorar el Salón de los Espejos, para cuyo techo había elegido Velázquez, ya en abril de ese año, el mito de Pandora ${ }^{21}$, en cuyo relato también se advierte de las consecuencias que pueden derivarse de no atender los consejos de los mayores. En cualquiera de ambas fechas - destinada al citado salón o por otro posible encargo del Montero de Cámara de Rey, pues constaba en su inventario- se trata de

19 Aunque esa parte del cuadro se restauró y amplió tras el incendio de 1734, seguiría el muro separando la escala de la fuente de la luz.

20 GÁlego, J. 1990: Velázquez. Catálogo. Madrid. Museo del Prado, Ministerio de Cultura, p. 420.

21 MOFFITT, J.F. op. cit. p. 95. 
una obra que prosigue los temas mitológicos que en esas fechas ocupaban la atención de Velázquez. Esos son también los años en los que Velázquez está tratando de alcanzar la nobleza. «En 1650 formuló ya petición al rey para ingresar en una orden militar, mientras que hacía campaña pública para conseguirlo" 22. Ambición que si bien alcanzó a finales de noviembre de 1659, había nacido en los años treinta y sufrido múltiples dificultades, siendo necesaria la directa intervención del rey y una dispensa papal ${ }^{23}$. No resulta difícil de aceptar que, tanto por la proximidad entre ambas obras, como porque el principal obstáculo para lograr la nobleza derivase del oficio de pintor, la crítica haya sugerido una interpretación similar en los dos casos: se trataría de mostrar la alta estima de la pintura como un arte que depende más del ingenio creador que de las manos, un arte superior al mero trabajo manual de pintar o hilar. Ahí está el pintor autorretratado, suspendiendo su mano en el momento de concebir la obra, junto a la familia real en las Meninas; o Aracne iluminada y "ataviada como La Poesía -que hace inmortales a los hombres $\longrightarrow{ }^{24}$. Tendríamos, como en otras obras de Velázquez, que el tiempo se representa con el despliegue del relato mitológico de Aracne en varios planos del lienzo. Las dos hilanderas del primer plano quedan elevadas a su verdadera condición en el fondo iluminado, como pretendía Velázquez elevar la pintura a su verdadera naturaleza espiritual, artística y noble.

Sin duda, el tema de la nobleza y la exención impositiva fue un problema que preocupó a Velázquez. Ésa es pues una de las posibles interpretaciones. Como señala Brown

"Las Meninas no es sólo un alegato abstracto en defensa de la nobleza de la pintura, es también una afirmación personal de la nobleza del propio Velázquez [...] Velázquez se propuso demostrar de una vez por todas que la pintura es un arte noble y liberal, que no se limita a copiar sino que puede recrear e incluso sobrepasar a la naturaleza. La pintura como vía legítima de conocimiento, pues, $y$, por lo tanto, más allá de cualquier oficio $y$, por lo tanto, de nuevo, un arte liberal [...] Con brillante osadía, Velázquez invita al observador a que juzgue digno al pintor en virtud, y no a pesar, de su arte» ${ }^{25}$.

22 BROWN, J. op. cit. p. 136.

23. Para un más amplio conocimiento de esa carrera en pos de la nobleza véase J.Brown op. cit. pp. 135-142.

24 MOFFITT, J.F. op. cit. p. 94.

25 BROWN, J. op. cit. p. 141 
Con todo, no era al rey ni a su montero de cámara, como potenciales observadores, en tanto que destinatarios de las citadas obras, a quienes tenía que convencer de la superioridad de su arte para lograr la ansiada nobleza, sino al Consejo de las Ordenes, que era el organismo que se oponía a ennoblecerle y de quien dependía la decisión. Habría pues que reconocer en el artista un afán expresivo independiente del encargo y del destino de la obra, para centrar en el honor de la pintura la interpretación de las Meninas y las Hilanderas. Es más, si tal honor pende del conocimiento que la pintura logra, lo que esa interpretación olvida es el contenido específico de lo conocido a través de esas pinturas. Probar la grandeza creadora de su arte es algo que mostró Velázquez con anterioridad y siempre con cualquiera de sus obras. Si en éstas es esa misma capacidad el tema ¿por qué lo prueba Velázquez con la infanta Margarita y con Aracne? ¿No hay además en este último caso un castigo a la ambición excesiva? ¿Está acaso Velázquez sugiriendo al rey, que ya está convencido y que es quien le apoya en su empeño, que le castigue como a Eva o como Minerva hizo con Aracne? ¿Es una reflexión sobre el exceso de su pretensión expresada en las Meninas, o es la expresión de un ruego de perdón?. Moffitt llega a sugerir que ya que Velázquez no llega a pintar el castigo efectivo de Aracne, Minerva perdona el exceso de la juventud. Sin embargo esta interpretación no estaría teniendo en cuenta una de las características del Barroco muy presente en toda la trayectoria de Velázquez: la sugerencia inacabada y escondida, el oscurecimiento de lo que se pretende significar como una dificultad cuya superación aumenta el goce del observador. No necesitaba pintar Velázquez, por tanto, la efectiva transformación de Aracne, ese final de la narración mitológica en la que se describe el castigo, para lograr el efecto que la narración producía en el observador capaz de descifrar una obra barroca. Más relevante resulta darse cuenta de que, en realidad, las Hilanderas toma algo que consta como mero fondo en las Meninas y lo tematiza.

En las Hilanderas se toma el tema del cuadro que cuelga en la pared del fondo de las Meninas, sobre la cabeza del autorretrato de Velázquez, una copia de Mazo del Minerva y Aracne del ennoblecido Rubens, y se desarrolla, del fondo al primer plano, ocupando enteramente la obra de Velázquez. Velázquez, por tanto, no termina en las Meninas la reflexión que allí inició. Como ocurre con otros pintores, bien por su lentitud, bien porque, como es en este caso, por colgar gran parte de sus obras en el mismo palacio en el que trabajaba, Velázquez convivió largo tiempo con sus obras. Esto le permitió sin duda ahondar en su investigación de lo que en ellas se trataba. La frecuencia de sus correcciones o arrepenti- 


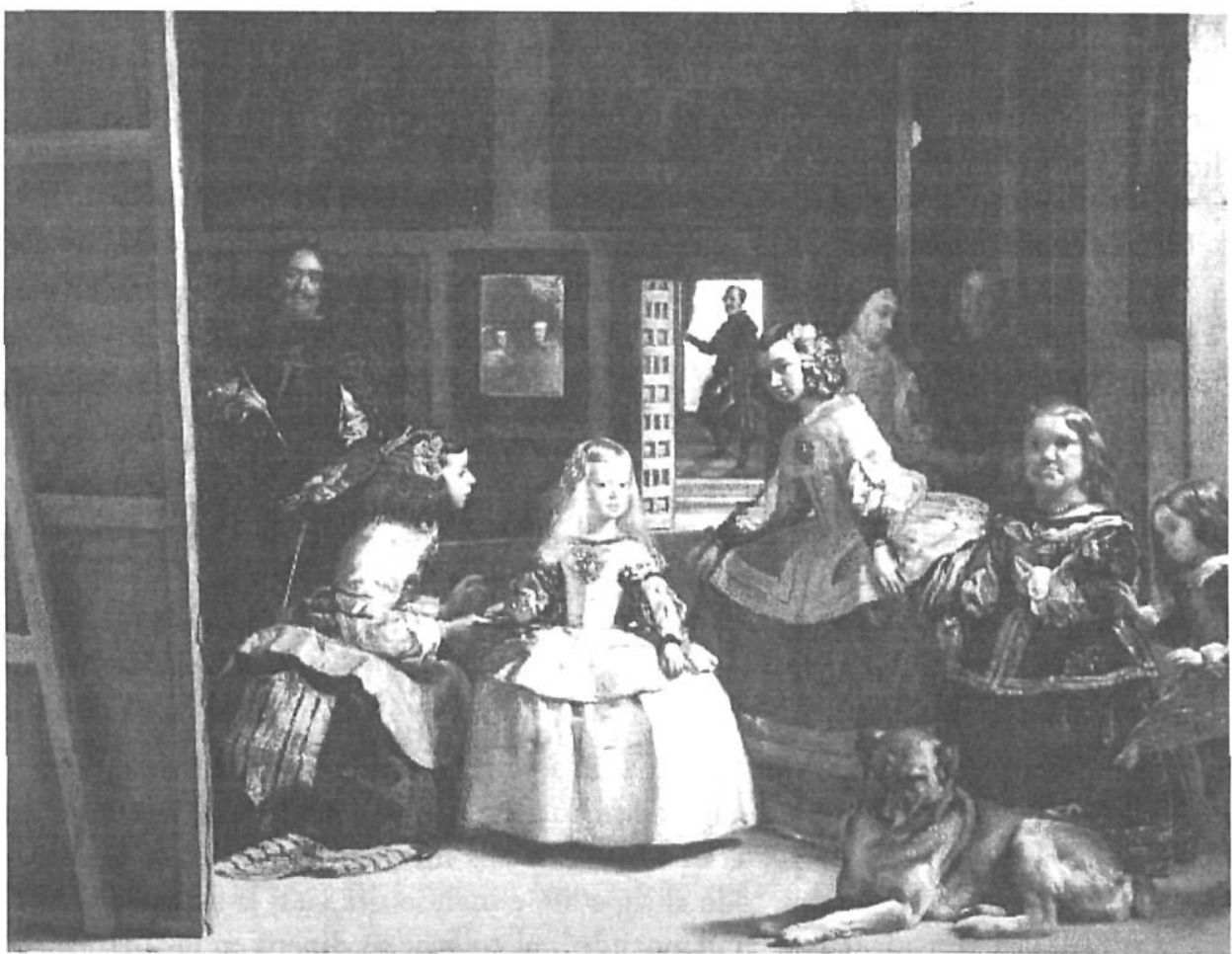

mientos, que tanto ha dificultado la datación de muchas de sus obras, no es sino una prueba de ese sostenido trabajo sobre unos mismos problemas. La ausencia de correcciones en las Hilanderas no se debe a que, por fin, lo tuvo bien claro Velázquez y resolvió el objeto de su estudio, sino a que fue una de sus últimas obras y no pudo contemplarla largo tiempo una vez hecha como en casos anteriores. Pero entonces ¿¿de qué es de lo que se trataba en las Meninas? ¿de lo mismo que en las Hilanderas?. Hay sin duda una continuidad entre las dos obras, pero no se limitan ambas al tema del honor de la pintura. Como ya sugerí en otra ocasión ${ }^{26}$, aquel honor se prueba con gran atrevimiento, haciendo en las Meninas un retrato mental del rey, mostrándole aquella preocupación dinástica causante de las facciones que Felipe IV veía al mirarse en el espejo: su familia, cuyo retra-

26 Sanmartín ArCe, R. 1992: Don Juan y las Meninas o la obediencia en el poder. Negaciones afirmativas para la creación simbólica. Huesca. Anales de la Fundación Joaquín Costa, n. ${ }^{\circ}$ 9, pp. 33-48. 
to colectivo pasó a colgar en su despacho, y su continuidad pendiente de aquella niña de cinco años, de cuya protección y honor pendía entonces, al ser ella la heredera, el honor de la monarquía, logrando así también mostrar toda su fragilidad en el inicio de la decadencia.

\section{La época como contexto}

Pero quizá sea contemplando los problemas de la época como podamos completar y mejorar la interpretación de las Hilanderas. Por época entendía Ortega "una especial comunidad $u$ homogeneidad de situaciones" ${ }^{27}$. Las que en el siglo XVII se dieron, a la vez que produjeron un Siglo de Oro, al que sin duda pertenece Velázquez, constituyeron la manifestación de una larga crisis que da lugar a la decadencia española, y cuyos orígenes encuentra Pérez en la derrota de los Comuneros en Villalar, en 1521. Derrota que

"consagra el triunfo de la monarquía; la aristocracia, frustrada de los beneficios políticos que esperaba de su participación en la victoria, se refugia en sus tierras y se dedica a la defensa de sus intereses económicos: la marea señorial sube durante todo el siglo XV e incluso después, la burguesía, dividida y vencida, sigue "traicionando", al colocar su dinero en las tierras; sus hijos se apartan del negocio y de la empresa y entran en las Universidades, en la función pública, en las Órdenes, si es que no se ven tentados por la aventura colonial o militar [...] el ideal de la renta [...] se vuelve la preocupación mayor de toda una sociedad y, junto a ese ideal, la sed de consideración social —afán de hidalguía-, la obsesión por la limpieza de sangre, valores en que se expresa la angustia de una sociedad cada vez más apartada de las realidades [...] Lo que desaparece en Villalar [...] es a buen seguro la libertad política y la posibilidad de imaginar otro destino distinto al de la España imperial, con sus grandezas y sus miserias, sus hidalgos y sus picaros. Lo que se preparaba bajo los Reyes Católicos y bajo Cisneros, una nación independiente y moderna, sin duda Carlos V lo abortón" ${ }^{28}$.

Sánchez Albornoz, Bennassar y Pérez, entre otros, muestran cómo la política de los Austrias marcó durante dos siglos la grandeza de un imperio sin

27 ORTEGA Y GASSET, J. 1971 (1942): Historia como sistema. Madrid. Espasa-Calpe, p. 96.

PÉrEZ, J. 2001: La España del siglo Xvı. Madrid. Espasa-Calpe, p. 248. 
unión, a la vez que dificultó la modernización. "España exporta la materia prima (la lana, sobre todo) e importa productos manufacturados, dejando al extranjero los beneficios de la transformación" ${ }^{29}$.

En una sociedad enormemente desigual, es no obstante el estilo de vida señorial, excepto en la aldea, el ideal vigente. Como señalaba Bennassar:

"Los nobles, los funcionarios, los letrados, los curas y los monjes no trabajan con sus manos, no se dedicaban al comercio, estaban libres de cargas y de contribuciones, vivían de sus rentas [...] Los demás los imitaban cuando podían. De ahí el gusto por los vestidos hermosos y las joyas, la frecuentación del teatro, el vocabulario en el que la palabra "honra" hace fortuna, el comportamiento fácilmente agresivo y violento. $\mathrm{Si}[\ldots]$ habían alcanzado cierto nivel de fortuna, abandonaban el artesanado o la mercancía por la golilla o las letras [...] compraban rentas: Los propios extranjeros sufrían la fascinación del modelon ${ }^{30}$.

Aun al precio del subdesarrollo, "lo que resulta imposible ignorar [...] es el esplendor de ese género de vida» ${ }^{31}$, en el que el "prurito de nobleza (afán de hidalguía) y preocupación por el honor [...] terminan por contaminar de arriba abajo toda la sociedad [engendrando] la esclerosis de la economía" ${ }^{32}$.

Tras lo estudiado por los historiadores, no es difícil reconocer en la carrera cortesana de Velázquez un buen ejemplo de aquella dorada sociedad del Barroco. Si además las dos obras que comento esconden en su oscuro ingenio, al modo de la época, la dignidad de la pintura y la ambición de su propio autor como tema, parecería que en ello debiéramos concluir la interpretación. Pero en tal caso ¿cómo veía Ortega en Velázquez una actitud contra la época? ¿cómo es que se autorretrata trabajando? ¿por qué se expresa esa valoración del trabajo más básico de las hilanderas que ocupa el primer plano? y ¿por qué.la lira? Velázquez fue testigo crítico de la época y no un mero receptor de su influjo. Como reconoce Calvo Serraller, Velázquez

«estaba obligado a vivir de cerca todos los dramas de palacio, que van a ser cada vez más tristes, pues no sólo mueren el heredero, [el] príncipe Baltasar

29 Ibid. p. 36.

30 Citado por Joseph PÉREZ op. cit. p. 257.

31 Ibid.p. 260.

32 Ibid. p. 43. 
Carlos [...] y la reina Isabel de Borbón [...] sino que también las noticias políticas y bélicas que afectaban a la monarquía hispana eran, a partir de la década de los treinta, una sucesión implacable de catástrofes" ${ }^{33}$.

El pintor de Las Lanzas y de un victorioso Conde-Duque, es a la vez "excepcional cronista de una hecatombe, cuyos matices psicológicos supo captar con escalofriante y honda veracidad ${ }^{34}$ en la sucesión de retratos de Felipe IV en la que se aprecia el peso de los años, de la creciente responsabilización del rey y de su preocupación por tantas pérdidas, desde el primero y mayor de ellos, de 1623, hasta el último y menor (si exceptuamos el captado en el espejo de las Meninas), entre 1655 y 1660 . Son ésos años en los que Velázquez está meditando sobre la dignidad de su oficio, aspirando a la nobleza, trabajando sobre los mitos, penetrando en el alma del rey y dando fe de lo que su discreta mirada veía como decadencia.

No es sólo Velázquez quien percibe crisis y decaimiento. Como señala C. Lisón, "toda una constante y amplia producción literaria barroca es un permanente jaque mate al rey en su extremado poder, un insistente recordatorio de sus obligaciones" ${ }^{35}$, y ello porque los escritores sienten las heridas de una crisis social que ven como fruto de los excesos y el mal gobierno. Las advertencias del conde de Peñaranda, de Zevallos, de Ribadeneyra y tantos otros, se suman a escritos anónimos que recibe el rey y que señalan cómo «el descuido de los que gobiernan es sin duda el artífice de la desventura y puerta por donde entran todos los males y daños en una república» ${ }^{36}$. En esos mismos años,

«Martín G. de Cellorigo veía que el mal no provenía de la guerra, sino "de la flojedad de los nuestros" [...] Sancho de Moncada, llegó a más: España se halla en grave peligro por ser "la gente toda tan regalada y afeminada". Ésta, aunque hoy nos parezca extraño —comenta Maravall- es estimación que se repite. [...] Pellicer de Tovar señala como causas de la penosa situación del país los regalos y afeminaciones. [...] Francisco de León, prior de Guadalupe [...] buscaba la raíz del mal [...en] "los hombres convertidos en mujeres, de soldados en afeminados, llenos de tufos, melenas y copetes y no sé si de

33 Op. cit. pp. 87-88.

34 Ibid. p. 13.

35 LISON TOLOSANA, C. 1991: La imagen del rey. Monarquía, realeza y poder ritual en la Casa de los Austrias. Madrid, Espasa-Calpe, p. 68.

36 Maravall, J.A. op. cit. p. 60. 
mudas y badulaques de los que las mujeres usan". [... apreciaciones tan reiteradas, comenta Maravall] muchas veces eran no otra cosa que un recurso retórico. Sin embargo nos ayudan a comprobar cómo la crisis del XVI había transformado la imagen de los españoles del siglo anterior, [...] nos dicen lo que de sensualidad, afán de placer, relajación y hasta lo de clara reacción contra la severidad de costumbres varoniles de otra época hay en el XVII» ${ }^{37}$.

De ahí que Velázquez citase a Miguel Angel y subrayara la transformación de los poderosos desnudos masculinos en mujeres. También encontró Velázquez un precedente similar en la obra de L. Cranach Hércules y Onfala, donde las mujeres cubren la cabeza de Hércules y le ponen a hilar como a la hilandera vieja.

Los jesuitas, por su parte, relatan rebeliones y alborotos en los que «juntóse muchísima gente común, como tejedores y otros, diciendo querían matar a los del gobierno de la ciudad porque no hallaban pan" ${ }^{38}$. Carencias que, como recogía Barrionuevo, llegaban hasta la mesa de palacio el mismo año en el que Velázquez pinta las Meninas:

"Dos meses y medio há que no se dan en Palacio las raciones acostumbradas, que no tiene el Rey un real, y el día de San Francisco le pusieron a la Infanta en la mesa un capón que mandó levantar porque hedía como perros muertos. Siguióle un pollo de que gusta, sobre unas rebanadillas como torrijas, llenas de moscas y se enojó de suerte que por poco no da con todo en tierra. Mire Vm. cómo anda Palacio. Todo esto es como lo cuento, sin añadir ni quitar un ápice»" ${ }^{39}$.

Paralelamente "la nobleza se sacudió de encima sus deberes militares" 40 , pudiendo María de Zayas denunciar cómo antaño "a pelear en las guerras "no era menester llevar los hombres por fuerza ni maniatados, como ahora" ${ }^{41}$. En esa misma apreciación coincide Álvarez Osorio al ver cómo "contra todas las leyes destos reynos, continuamente llevan a los pobres jornaleros por fuerza a

37 Ibid. pp. 93-95.

38 Ibid. p. 109.

39 ORTEGA y GASSET, J. 1983, op. cit. p. 104.

40 Maravall, J.A. op. cit. p. 119.

41 Ibid. p. 120. 
los ejércitos» ${ }^{42}$. Y, tensando los límites sostenibles en tales situaciones, en toda Europa

«la nobleza, si con sus hábitos suntuarios sustrae de la posible inversión productiva una parte importante de los ingresos, agravando una situación de crisis económica [...] no deja de exigir una mayor reserva para ella de los puestos honoríficos en la función pública, con sus rendimientos pecuniarios; a la vez, reclama el mantenimiento de los signos externos que diferencian a los individuos de diferentes estamentos, en el vestir, [...] en lugar de entregarse al ejercicio de la manufactura, o del comercion" 43 .

A diferenciarse y escalar en la sociedad aspiran todos, hasta el punto en el que no pudiéndolo lograr, el crecimiento del malestar "se reconoce proceder de una desorbitada expansión de las aspiraciones» ${ }^{44}$. También "Quevedo relacionaba la locura del mundo en su tiempo con la desmesura de la pretensión que a todos impulsa a subir a más" ${ }^{45}$. Parece tratarse de un siglo que, si bien lo es «del descontento lo es también de la búsqueda del "medro", del éxito, de la ostentación de la riqueza, con un afán de inserción en el mundo incontenible, de afirmación triunfante sobre el suelo movedizo de la sociedad" ${ }^{46}$. No cabe duda que en ello, como observa Maravall, «se reconoce [...] un primitivo y confuso esquema [...] de la sociedad de concurrencia. El dogma burgués de la libre competencia procederá de ese fondo" 47.

No es por tanto una creación cultural madura, sino el amanecer en el horizonte de algo que, desde la inmadurez del esbozo y la inquietud del reto, reclama la atención de los creadores como una inevitable pregunta. Es más, lo que a toda la sociedad embarga, alcanza también al destino del rey. Las palabras de Olivares alentando la ambición de Felipe IV parecen una versión de las de la serpiente a Eva: "seréis como Dios», instándole al logro del dominio y unión de los reinos, puesto «que si V. Majd. lo alcanza será el príncipe más poderoso del mundo" ${ }^{48}$.

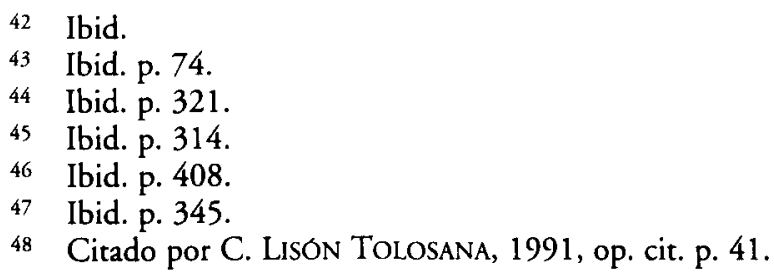


Si el así descrito era el efectivo fondo sociocultural de la época, es frente a él como cabe intentar comprender lo que en las obras más libres y maduras de Velázquez se expresa. Inserta en esa línea de trabajo sobre los mitos, no cabe negar a sus obras un contenido moral. Como señalaba Hatzfeld, los artistas en esa época use sintieron compelidos a sacar de su propia experiencia en la vida los valores olvidados de la antigüedad, y a usar los modelos tradicionales, humanístico-mitológicos como contraste»" ${ }^{49}$. También John M. Wallace destaca cómo en el XVII los artistas, «si deseaban moralizar sobre asuntos de la época [...] tenían (primero) que encontrar la fábula adecuada" ${ }^{50}$. Parece pues que en la de Aracne Velázquez la encontró.

\section{Interpretación}

Volvamos pues al cuadro de las Hilanderas e intentemos, frente al fondo de esa época, completar las interpretaciones ya ofrecidas que centran en el honor de la pintura su sentido. Veamos cómo junto a esa dignidad esconde Velázquez su personal penetración en la época, trayendo a colación, a modo de citas académicas, esa pluralidad de fuentes de la tradición para moralizar contra la época. Desde las Metamorfosis de Ovidio, hasta el Rapto de Europa de su contemporáneo P.P. Rubens, pasando por la Eva de C. Robetta, el Hércules y Onfala de Cranach o los Ignudi de Miguel Angel, Velázquez está empapando sus pinceles en la pluralidad de ideas que con tan variadas fuentes acuden a su cita. La plasticidad y simultaneidad de un cuadro permite estrategias expresivas que la progresión diacrónica de otras artes no tolera. Y, aunque todas las artes dicen muchas cosas a la vez, quizá la pintura lo logra de un modo más rotundo, más acorde con su propia naturaleza. Es así como consigue Velázquez unir, como un compositor, varias voces sin que la suma resulte disonante. De ahí que pueda, a la vez que aboga por la más alta dignidad del arte, penetrar en la preocupación del alma del rey y formular una crítica a su época.

Ya vimos cómo en las Meninas Velázquez daba un paso decisivo en la capacidad investigadora del retrato. Si tras la serie de retratos de Felipe IV, progresivamente menores y centrados en el rostro, al llegar a las Meninas penetra en su

49 Op. cit. p. 413.

so Citado por J.F. MoffitT, op. cit. p. 99. 
interior mostrando lo que causa la expresión del rostro, en las Hilanderas da una paso que va del rey al reino, del individuo a la sociedad, del sujeto a su época, adentrándose en el cuadro de Aracne que quedó al fondo de las Meninas y trayéndolo a la luz. ¿Qué es pues lo que la luz de su mano nos muestra? Un total de diez figuras femeninas cuyos rostros, huyendo del retrato, quedan sólo sugeridos, valiendo sólo como caracteres genéricos. No son nadie real o concreto sino gente, como diría Ortega, esto es, sociedad dividida en dos planos y niveles. El primer plano, más visible, aunque menos iluminado, lo componen cinco obreras del taller de tapices. Las dos figuras principales representan a Minerva y Aracne como dos hilanderas. Unidas a las otras tres, inclinadas y trabajando, representan bien los estamentos bajos de la sociedad. Al fondo del cuadro, en esa estancia elevada e iluminada, ante el tapiz, tres damas con sus manos ociosas y de nuevo Minerva y Aracne: otras cinco figuras en representación de la nobleza y la jerarquía de una sociedad marcadamente diferenciada. El esquema compositivo encaja bien con la interpretación propuesta por la crítica, pues permite representar ese nivel superior que corresponde al arte de la pintura simbolizado en el tapiz, frente al simple trabajo manual de las hilanderas. Pero lo que quisiera destacar es cómo para crear ese significado se hace uso de la diferenciación social propia de la época y, a la vez, se separa ambos niveles mediante un par de escalones cuya altura es algo superior a los noventa centímetros ${ }^{51}$, esto es, mediante una medida muy incómoda de superar dado el tamaño de los hombres de la época, subrayando la extrema dificultad que implica el paso de un nivel al otro. Al honor de la pintura, por tanto, se suman otros significados. En el nivel superior además del tapiz está la viola como símbolo adicional del arte. Con todo, Angulo ${ }^{52}$ sugiere que dicho instrumento consta como una pista más que ayuda a identificar la fábula, pues se trata de uno de los instrumentos cuyo sonido curaba, según las creencias de la época, la picadura de la araña. No obstante, se trata de un instrumento que requiriendo como todos del ejercicio manual para que suene, está dejado en silencio sobre una silla, un mueble ideado para el descanso. Ese tránsito de un nivel al otro, eso a lo que toda la sociedad aspira, no se alcanza sin el esfuerzo y sin la aplicación de las manos al instrumento. La curación de la ambición, si ha de darse, exige pues trabajo. Si el veneno de la araña es, en esta fábula, la ambición excesiva, y su curación el esforzado ejercicio que el arte de la música representa, bien pudo connotar en

$51 \quad$ Véase J.F. MoffiTT op. cit. p. 249.

52 Op. cit. p. 112. 
la época, sobre ese trasfondo de problemas, una crítica al estado de una cultura en la que se ambiciona demasiado sin poner los medios, en la que por perseguir las rentas e ideal de una vida nobiliaria los hombres todos han perdido aquella complexión con que los representó Miguel Angel, pareciendo ahora más bien damas o hilanderas. A causa de una ambición tan excesiva como la de Eva fue castigada Aracne, cuando planteó la competición entre contendientes cuya diferencia implica la distancia que media entre el don divino y la limitación de los mortales. La obra, pues, usando el mito para moralizar como se hacía en el Barroco, parece sugerir cómo se vio obligada la Corona a pender colgada de su propia creación imperial de la misma manera que Aracne, quedando la herencia del reino encerrada en esa semilla de rey que era el infante Felipe Próspero, a los pies de su destino.

En aquellos espacios donde la sociedad ve nacer sus nuevos problemas, donde la cultura todavía no ha encontrado normas, nombres, principios, estrategias adecuadas o suficientes para tratarlos, ahí es donde el artista creador concentra su atención y, desde la ficción, intenta alumbrar esa nueva realidad que emerge, exorcizándola al menos con el rito de su creación, retirando ese velo de silencio que la cubre, dándole con su voz un nombre o una imagen a modo de primer cuerpo reconocible. Reconocible a pesar de que Velázquez se encarga de cubrirlo con el ropaje ficticio del realismo, de la naturalidad de la vida cotidiana, cifrando sus mensajes para intensificar el gozo de descubrirlo. A esa estrategia suma una cuidada ambigüedad al presentar el tapiz del Rapto de Europa sin mostrar la cenefa inferior. De ese modo no queda claro si Minerva y Aracne están pie en tierra como las damas, como personajes reales o si forman parte del tapiz que las damas contemplan. La continuidad creada de ese modo entre ficción y realidad no es vana, sino que hace más complejo el sentido del cuadro. El tapiz que encierra una escena mitológica es fruto del tejer e hilar de las mujeres. Pero es el mito el que ilumina e interpreta lo que ocurre en la sociedad que lo crea. La continuidad entre realidad y ficción es creadora en ambos sentidos, se sostienen mutuamente. Del mismo modo que el mito también el arte es fruto de la sociedad, y a ella vuelven ambos iluminando su propia fuente. Como el trabajo manual y el noble ingenio de cuyo concurso nace el arte. No cabe pues separar la nobleza del arte y su esfuerzo. Bien lo supo Velázquez que no pudo zafarse de la manualidad de su don para aspirar a su nobleza. Por propia experiencia ideó el enmarañado diseño de la Fábula de Aracne, y desde él se atrevió a nombrar los males del imperio que atisbaba al escrutar el horizonte de su época. 


\section{Bibliografía}

ANGULO INIGUEZ, D. 1999 (1947): Velázquez. Cómo compuso sus principales cuadros y otros escritos sobre el pintor. Istmo. Madrid.

BrowN, J. (1988): Imágenes e ideas en la pintura española del siglo XVII. Alianza Forma. Madrid.

Calvo Serraller, F. (1999): Velázquez. Península, Barcelona.

Gállego, J. (1990): Velázquez. Catálogo. Madrid. Museo del Prado, Ministerio de Cultura.

HATZFELD, H. (1972): Estudios sobre el Barroco. Editorial Gredos, Madrid.

LAFUENTE FERRARI, E. (1999): Velázquez o la salvación de la circunstancia. Institució Alfons el Magnànim. Valencia.

LisÓN TOLOSANA, C. (1991): La imagen del rey. Monarquía, realeza y poder ritual en la Casa de los Austrias. Madrid, Espasa-Calpe.

- (2000): El conde-duque de Olivares en corveta regia. Una mirada desde la Antropología. Anales de la Fundación Joaquín Costa, Huesca.

MARAVALl, J.A. (2000): La cultura del Barroco. Ariel, Barcelona.

Mena MARQues, Manuela B. (1996): «Velázquez e Italia: Las metamorfosis del arte de la pintura» en Velázquez. El Papa Inocencio X de la Galleria Doria Pamphilj, Roma. Catálogo. Madrid. Museo del Prado.

MoffiTT, J.F. (1991): Velázquez, práctica e idea: estudios dispersos. Universidad de Málaga y Colegio de Arquitectos en Málaga.

ORTEGA Y GASSET, J. (1971) (1942): Historia como sistema. Madrid. Espasa-Calpe.

- (1983) (1946): Goethe-Dilthey. Madrid, Revista de Occidente en Alianza Editorial.

- (1983) (1947): Velázquez. Espasa-Calpe, Madrid.

Palomino, A. (1797): El museo pictórico y escala óptica. Tomo segundo, Madrid.

PÉrez, J. (2001): La España del siglo XVI. Madrid. Espasa-Calpe.

SANMARTIN ARCE, R. (1992): Don Juan y las Meninas o la obediencia en el poder. Negaciones afirmativas para la creación simbólica. Huesca. Anales de la Fundación Joaquín Costa, $n .^{\circ} 9$.

- (1993): Identidad y creación. Ed. Humanidades, Barcelona. 